\title{
Stress, strain, and mountain building in central Japan
}

\author{
John Townend ${ }^{1}$ and Mark D. Zoback ${ }^{2}$ \\ Received 3 April 2005; revised 18 September 2005; accepted 16 November 2005; published 28 March 2006.
}

[1] The work described here has two key objectives: to investigate the geometric relationships between the principal directions of crustal stress and crustal strain rate in central Japan and to evaluate how crustal stresses are related to the rates of horizontal strain produced by different tectonic processes. Specifically, we consider the extent to which tectonic stress directions reflect transient deformation produced by interseismic subduction thrust locking. The axis of maximum horizontal compressive stress obtained from focal mechanism inversion agrees well with the axis of greatest contractional strain rate in central and southwest Japan only after the effects of interseismic strain accumulation on geodetic observations have been accounted for according to an elastic dislocation model of subduction thrust locking. The residual deformation, which is presumed to represent net upper plate deformation, is broadly confined to the area of pronounced topography in central Japan and is consistent with the deformation expected for horizontal motion of the Amurian plate with respect to northeastern Honshu. These observations suggest that part of the apparent discrepancy between crustal stress and strain rate directions reported by previous authors stems from a comparison of parameters representing processes occurring on different timescales. In this case, the strain rates associated with cyclic subduction zone locking are not reflected in the crustal stress field; conversely, longterm horizontal motion between northeast and southwest Japan exerts a stronger influence on the crustal stress field and neotectonic mountain-building processes in central Japan than do intermittent subduction zone earthquakes.

Citation: Townend, J., and M. D. Zoback (2006), Stress, strain, and mountain building in central Japan, J. Geophys. Res., 111, B03411, doi:10.1029/2005JB003759.

\section{Introduction}

[2] In this paper, we address the question of how tectonic stresses in the crust, as estimated using focal mechanism data, are related to horizontal strain rates measured geodetically. We focus on central Japan, where two potential sources of tectonic deformation (interseismic locking of the Nankai Trough and Japan Trench subduction thrusts and relative motion between southwestern and northeastern Honshu) appear to exist and where topographic and heat flow data provide a means of linking long-term deformation and mountain building to crustal stresses, strain rates, and thermal conditions.

[3] As originally proposed, global plate tectonic theory presumes there to be no internal deformation of the plates and thus cannot be straightforwardly reconciled with either distributed intraplate deformation or seismicity [cf. Gordon, 1998; Thatcher, 1995]. While structures of all scales accommodate such deformation, kinematic data alone do not

\footnotetext{
${ }^{1}$ School of Earth Sciences, Victoria University of Wellington, Wellington, New Zealand.

${ }^{2}$ Department of Geophysics, Stanford University, Stanford, California USA.

Copyright 2006 by the American Geophysical Union. 0148-0227/06/2005JB003759\$09.00
}

explain how intraplate faults actually accomplish this. At the very least, determining how the rheology of the lithosphere is related to deformation mechanisms operating at much smaller scales requires that the ambient stress and strain conditions both be known.

[4] Our motivation for studying intraplate stress in Japan is to provide a means of interpreting crustal seismicity in the context of longer-term deformation and of relating a discrete, stress-mitigated brittle failure mechanism to regional distributed crustal strain. This is a somewhat pragmatic goal because it may provide a means of relating intraplate crustal earthquakes to geodetic deformation; at present, the vast majority of the earthquakes recorded at local and regional scales are too small to be readily compared with geodetic signals, as the associated coseismic strains are too small be detected with surface-based instruments. Computing stress parameters [e.g., Angelier, 1979, 1984; Michael, 1984; Gephart, 1990; Abers and Gephart, 2001] instead of strain parameters makes it possible to work with small-magnitude earthquakes whose negligible contribution to a region's total moment release is overwhelmed in focal mechanism summations [e.g., Kostrov, 1974; Lewis et al., 2003] by that of larger earthquakes.

\subsection{Contemporary Crustal Deformation}

[5] The four main islands of Japan, which together form the upper plate of the Nankai Trough and Japan Trench 


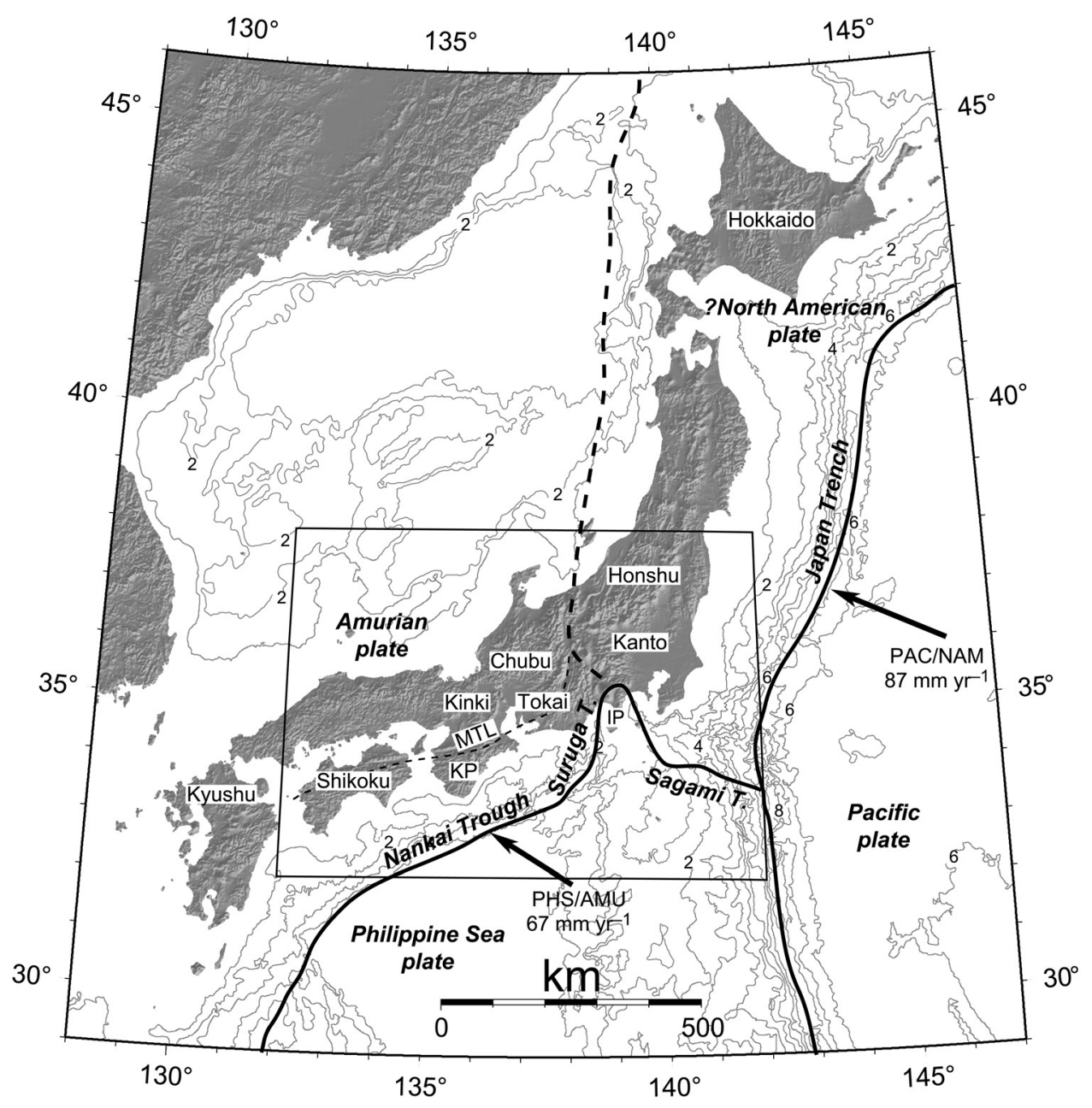

Figure 1. Map of Japan showing the principal tectonic elements and their relative motions. The box enclosing central Japan indicates the area shown in Figures 2, 5, and 6. IP, Izu Peninsula; KP, Kii Peninsula; MTL, Median Tectonic Line. Faults and plate boundaries after Heki et al. [1999] and Miyazaki and Heki [2001].

subduction zones (Figure 1), are composed of the Amurian plate, the North American or Okhotsk plate, and several microplates that behave as coherent tectonic units but whose boundaries and velocities with respect to one another remain equivocal [e.g., Heki et al., 1999; Sagiya et al., 2000; Henry et al., 2001; Mazzotti et al., 2001; Miyazaki and Heki, 2001]. In southwestern Japan, the Philippine Sea plate (PHS) is being subducted beneath the Amurian plate (AMU) along the Nankai Trough at a rate of $63-68 \mathrm{~mm} \mathrm{yr}^{-1}$ toward $305^{\circ}$ [Miyazaki and Heki, 2001]. In central Japan, the Zenisu and Izu-Bonin ridges collide with the Kanto region; microseismicity and geodetic data suggest that the subducting Philippine Sea plate is torn or at least strongly bent beneath Kanto, due to the complexity of subduction along the Sagami and Suruga troughs [Ishida, 1992; Mazzotti et al., 1999]. Both the Tokai and Kanto forearc regions exhibit significant motion with respect to the Amurian plate [Henry et al., 2001; Mazzotti et al., 2001]. The subduction geometry along the northeastern coast of Honshu is somewhat simpler than that in central and southwestern Japan, although the relationship of the upper plate to either the Amurian plate or the North American/
Okhotsk plate is unclear [Mazzotti et al., 2001]. The Pacific plate (PAC) is subducting beneath the northeastern Honshu arc at a velocity similar to the NUVEL-1A Pacific-North America (NAM) prediction [Mazzotti et al., 2000; DeMets et al., 1994].

[6] The task of delineating the plates, microplates, or crustal blocks present in central Japan and determining their relative velocities is complicated by the much larger strain rates associated with interseismic loading than with secular plate motions [Wang, 2000; Henry et al., 2001; Mazzotti et al., 2001; Miyazaki and Heki, 2001; Tabei et al., 2003]. Conversely, the stresses associated with interseismic locking are much smaller than the secular tectonic stresses on which they are superimposed: The former are typically estimated to be of the order of 0.1-1 MPa [e.g., Zhao et al., 2004], whereas midcrustal differential stresses inferred from extrapolations of deep borehole measurements exceed $100 \mathrm{MPa}$ [Townend and Zoback, 2000], as predicted by frictional faulting theory for hydrostatic fluid pressure conditions [Sibson, 1974; Brace and Kohlstedt, 1980]. It is important therefore to distinguish deformation associated with interseismic strain accumulation and the earthquake 


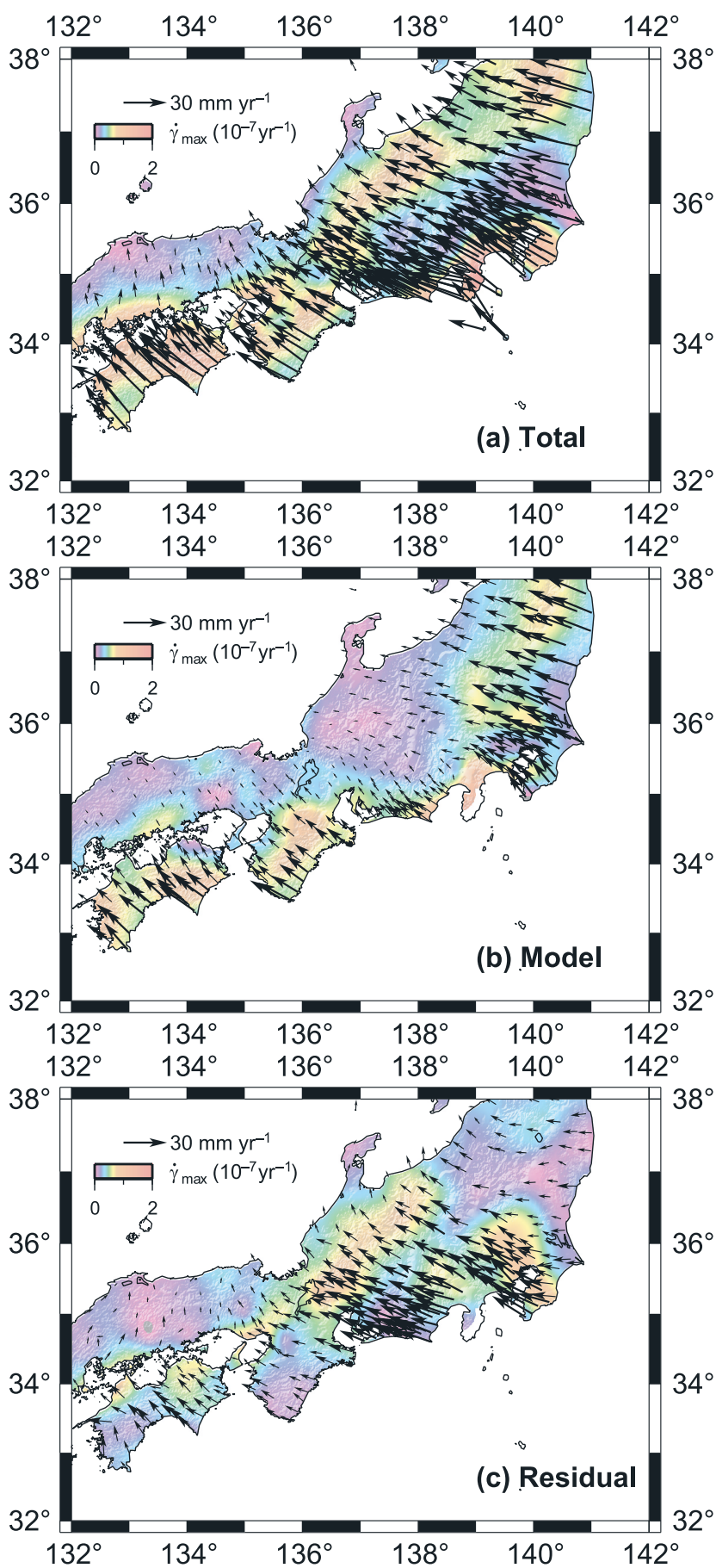

Figure 2. Crustal velocities relative to the Amurian plate in central Japan overlain on maps of maximum shear strain rates, $\dot{\gamma}_{\max }=\left(\dot{\epsilon}_{1}-\dot{\epsilon}_{3}\right) / 2$ (data modified after Mazzotti et al. [2001]). (a) "Total" data corresponding to the observed velocities and corresponding strain rates [cf. Mazzotti et al., 2001, Figure 2b]. (b) "Model" data corresponding to the predictions of an elastic dislocation model. (c) "Residual" data corresponding to the difference between the total and model data [cf. Mazzotti et al., 2001, Figure 3b]. See text for further details. cycle from any irrecoverable deformation associated with relative plate motions in order to compare tectonic stress and strain patterns.

[7] Mazzotti et al. [2001] subtracted the calculated effects of contemporary subduction interface locking from the total (observed) deformation field in central Japan to obtain a residual deformation field they interpreted to correspond to long-term deformation of central Japan (Figure 2). The authors estimated the deformation associated with interseismic locking using an inverse model of back slip on the subduction thrusts [Mazzotti et al., 2000; Henry et al., 2001]. A similar decomposition of the geodetically measured deformation field in southwest Japan (west of approximately $137^{\circ} \mathrm{E}$ ) was made by Miyazaki and Heki [2001], who used a forward model of interseismic locking in the Nankai Trough. In each case, the geometry of each subduction thrust was inferred from seismicity profiles, and each thrust was assumed to be uniformly locked between updip and downdip transition zones [Hyndman et al., 1995] in which coupling was linearly tapered.

[8] In studies such as those of Mazzotti et al. [2001] and Miyazaki and Heki [2001], the residual deformation field depends directly on the particular elastic model of interseismic locking being employed and discretion must be used in interpreting the residual component of deformation as anything other than mismodeling [cf. Wallace et al., 2004]. The forward modeling approach has the advantage of avoiding contamination of the locking estimate by processes other than locking alone. Importantly, however, where the Mazzotti et al. [2001] and Miyazaki and Heki [2001] studies overlap, they yield comparable residual strain rate patterns, which correspond well with the pattern of crustal deformation expected on geological grounds for the collision of the Amurian plate with northeastern Japan.

[9] Specifically, the localization of high strain rates $\left(100-200 \times 10^{-9} \mathrm{yr}^{-1}\right)$ within a $100-\mathrm{km}$-wide zone extending across the Kinki region from the Median Tectonic Line to the northern Japanese Alps is consistent with the geographic distribution of faults thought to have been active during the Quaternary, paleoseismic estimates of Quaternary strain rates and independent triangulation estimates, and the predicted motion of the Amurian plate with respect to northeastern Japan [Mazzotti et al., 2001]. Moreover, the residual strain rate data exhibit a distinct region of low strain rates in southwesternmost Honshu, which is thought on independent grounds to deform relatively little [Heki et al., 1999].

[10] Therefore, while any residual strain might be ascribed to the use of an inappropriate locking model, the general similarities between the Mazzotti et al. [2001] and Miyazaki and Heki [2001] studies' results in spite of the different methodologies employed suggest that the residual strain is not an artifact of unrealistic locking estimates. For the purposes of this work, therefore, we treat the deformation field obtained by subtracting a model of interseismic locking effects from the observed deformation measurements as representative of long-term upper plate deformation related to secular crustal motions in central and southwestern Japan and refer to it as "residual strain."

[11] We focus below on comparing the stress results with the strain rate fields presented by Mazzotti et al. [2001] and briefly summarize their locking model here for reference; 
full details are given in their earlier papers [Mazzotti et al., 2000; Henry et al., 2001], as indicated. The southern Japan Trench is treated as fully locked between the trench and $55 \mathrm{~km}$ depth with a subduction velocity of $81 \mathrm{~mm} \mathrm{yr}^{-1}$ toward $311^{\circ}$ and a linear transition to free slip beneath $70 \mathrm{~km}$ [Mazzotti et al., 2000]. The Sagami Trough is modeled as being fully locked between $5 \mathrm{~km}$ and $25 \mathrm{~km}$ depth with a PHS/Kanto subduction velocity of $26 \mathrm{~mm} \mathrm{yr}^{-1}$ toward $336^{\circ}$ and upper and lower transitions in the $0-5 \mathrm{~km}$ and $25-30 \mathrm{~km}$ depth ranges [Henry et al., 2001]. The eastern Nankai-Suruga Trough is fully locked between the trench and $20 \mathrm{~km}$ depth, with a $10-\mathrm{km}$-wide transition to free slip beneath $30 \mathrm{~km}$ depth [Henry et al., 2001]. Subduction of PHS beneath the Tokai region is described by rotation at $-5.6^{\circ} \mathrm{Myr}^{-1}$ about a pole located at $\left(139.8^{\circ} \mathrm{N}, 36.4^{\circ} \mathrm{N}\right)$. Finally, the central Nankai Trough is treated as being fully locked between $8 \mathrm{~km}$ and $25 \mathrm{~km}$ depth, with updip and downdip transitions over the $0-8 \mathrm{~km}$ and $25-$ $33 \mathrm{~km}$ depth ranges, respectively, and a subduction velocity of approximately $40 \mathrm{~mm} \mathrm{yr}^{-1}$ toward $311^{\circ}$ [Mazzotti et al., 2000]. In each case, the geometry of the subduction interface used in the dislocation modeling is that obtained by Ishida [1992] by contouring the upper surface of inclined planes of seismicity beneath central Japan.

\subsection{Previous Stress Orientation Studies}

[12] The pressure (P) and tension (T) axes of a moment tensor or focal mechanism are often mistakenly equated with the axes of maximum $\left(\mathrm{S}_{1}\right)$ and minimum compressive stress $\left(\mathrm{S}_{3}\right)$, respectively. However, the two sets of axes are not necessarily coaxial, and conflation of the two has led to some confusion in the literature about what stress information a moment tensor or focal mechanism conveys. In fact, depending on the relative magnitudes of the principal stresses, the axis of maximum (minimum) compressive stress need only lie somewhere within the dilatational (compressional) quadrant of the focal sphere for a fault to slip in the direction of resolved shear traction [McKenzie, 1969; Aki and Richards, 1980]. In this paper, we have attempted to differentiate between the two sets of terminology wherever possible. For comparison with the horizontal strain rate estimates, we mainly focus on the axis of maximum horizontal compression, $S_{\mathrm{Hmax}}$.

[13] Nakamura and Uyeda [1980] offered a generalization of the state of stress in Japan based on patterns of stress seen in island arcs elsewhere, most importantly in the Aleutians. They argued for trench-normal compression in the accretionary wedge, arc-normal strike-slip faulting in the immediate vicinity of the volcanic arc, and arc-normal extension in the back-arc area. In order to test this and other models, several authors [Shiono et al., 1980; Tsukahara and Kobayashi, 1991; Tsukahara and Ikeda, 1991] have estimated the azimuth of $S_{\mathrm{H} \max }$ throughout central and western Honshu using average focal mechanism $P$ axes and a very limited number of in situ stress measurements at depth. However, the procedure used to estimate $S_{\text {Hmax }}$ in these studies is based on a frictional failure criterion applied to individual earthquakes: The uncertainties in stress orientation $\left( \pm 30^{\circ}\right)$ are not appreciably less than those that would arise from simply treating the $\mathrm{P}$ axis as $\mathrm{S}_{1}$ $\left( \pm 45^{\circ}\right)$. Nevertheless, these and other authors have commented on a general pattern of SW-NE trending $S_{\text {Hmax }}$ in southern Honshu and Kyushu, and an approximately NWSE orientation in northern Honshu.

[14] Seno [1999] accounted for the orientations of earthquake $\mathrm{P}$ and $\mathrm{T}$ axes throughout Japan using a simplified model of the regional plate configuration and driving forces. With the exception of Kyushu and Hokkaido, the Japanese stress field was concluded to be reasonably explained via long-range ridge push and slab pull forces on which are juxtaposed the effects of variable cross-arc topography and crustal thickness. Overall, however, the average P axis orientation in southwestern Japan has proven difficult to reconcile with the SE-NW direction of convergence between the Philippine Sea plate and the overlying arc. Several researchers have investigated stress states within the upper plate using numerical models [e.g., Hassani et al., 1997; Wang and He, 1999; Zhao and Takemoto, 2000; Baba et al., 2001; Hyodo and Hirahara, 2003]. In each of these models, the effective coefficient of friction on the main subduction thrust plays an important role in controlling stresses in the forearc.

\section{A Consolidated Focal Mechanism Catalog}

[15] In order to conduct comprehensive focal mechanism inversions to map stress orientations and relative magnitudes throughout central Japan, we have combined and synthesized three independently recorded earthquake phase data catalogs (arrival times and first motion polarities): the Japan Meteorological Agency (JMA) catalog, the Japan University Network Earthquake Catalog (JUNEC), and the National Research Institute for Earth Science and Disaster Prevention's Kanto-Tokai Network Catalog (KTK). The first two catalogs include data recorded by a national array of seismometers, whereas the KTK network is concentrated primarily in central Japan between latitudes $33.5^{\circ} \mathrm{N}$ and $36.5^{\circ} \mathrm{N}$ and longitudes $135^{\circ} \mathrm{E}$ and $142^{\circ} \mathrm{E}$. Merging the different data sets is complicated by the fact that they not only contain different numbers of earthquakes, but also contain slightly different hypocentral parameters for those earthquakes that they do in fact share in common. We first merge the JMA and JUNEC catalogs, and then merge the result with the KTK data to produce the final consolidated catalog. In each of the two steps, an event in one catalog is presumed to be represented in the other if it occurred within a given time $(10 \mathrm{~s})$, horizontal distance $\left(0.65^{\circ}\right)$, and vertical distance $(60 \mathrm{~km})$ of an event. In practice, the timing constraint alone is sufficient to match most earthquakes, and the average origin time difference is generally $<1 \mathrm{~s}$.

[16] Hypocenters were recomputed for the consolidated $\mathrm{P}$ and S phase data using Hypoinverse 2000 [Klein, 2002] with $\geq 8$ arrivals, $0.1 \mathrm{~s}$ standard timing error, standard distance and residual weighting parameters, and the Ukawa et al. [1984] Kanto-Tokai velocity model. We computed focal mechanisms using Fpfit [Reasenberg and Oppenheimer, 1985] and tolerant quality parameters ( $\geq 8$ first motions, $500 \mathrm{~km}$ maximum epicentral distance, all magnitudes, and default error rates).

[17] Merging the phase data produces an overall improvement in the average number of $\mathrm{P}$ and $\mathrm{S}$ arrival data for each event (an average of 102 combined arrivals for the $\sim 16,000$ earthquakes recorded by all three networks, compared to 54 , 21 , and 25 arrivals reported by the KTK, JUNEC, and JMA 


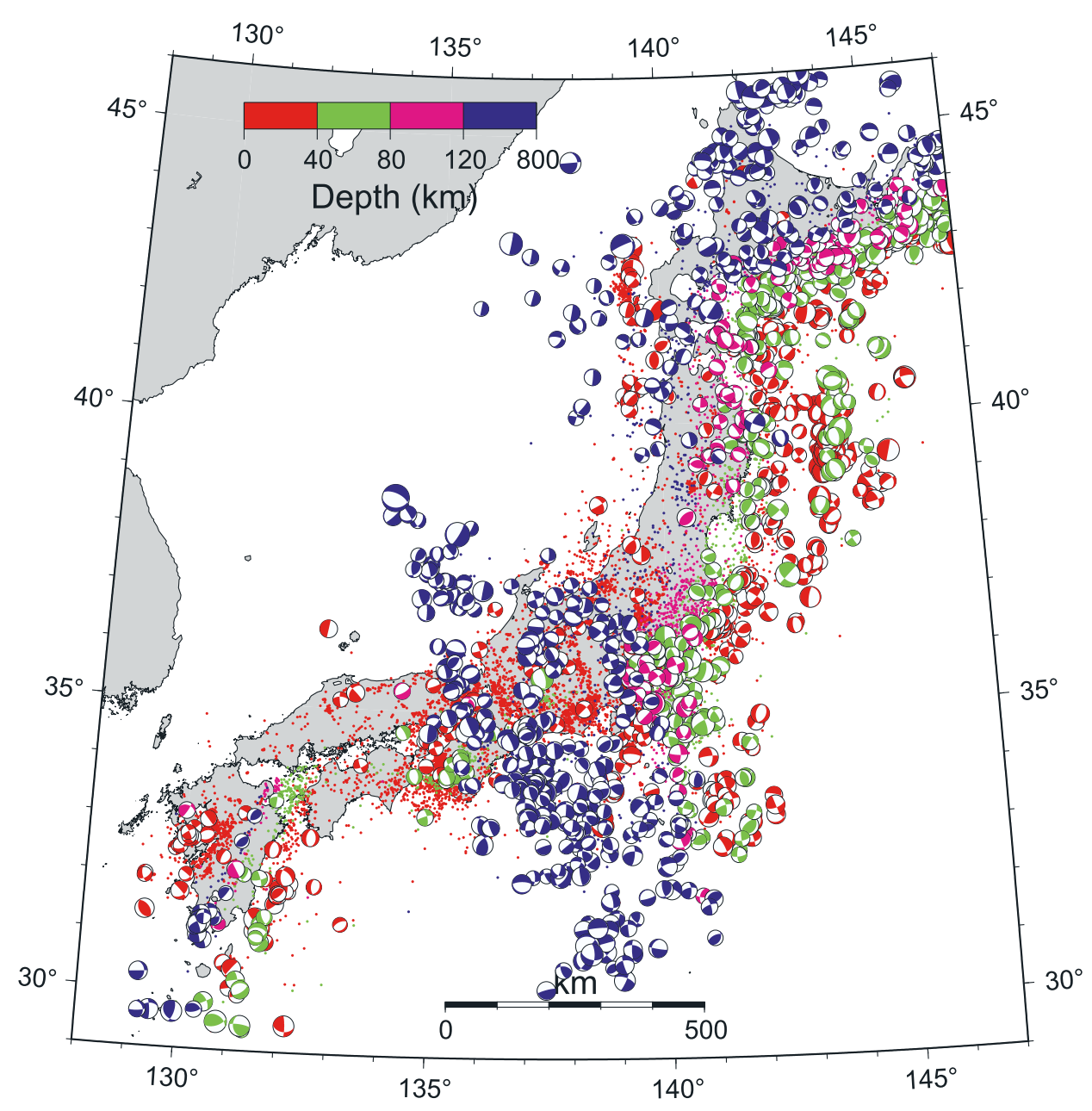

Figure 3. Consolidated focal mechanism catalog used in this study. Beach balls have only been drawn for those earthquakes larger than $M 4$.

networks individually) and the station geometry (in terms of the maximum azimuthal gap, which decreases from $>120^{\circ}$ to $73^{\circ}$ on merging), and correspondingly smaller travel time residuals and standard errors with respect to the hypocenters computed using phase information from a single data set alone. Computing focal mechanisms with the consolidated catalog yields approximately 25,000 well-resolved focal mechanisms, of which almost 9000 have strike, dip and rake uncertainties of less than $10^{\circ}$ (Figure 3).

\section{Tectonic Stress Directions in Central Japan}

[18] All methods of estimating principal tectonic stress directions from focal mechanism data are based on the presumption that faults slip in the direction of maximum resolved shear traction, commonly referred to as the "Wallace-Bott hypothesis" [McKenzie, 1969]. Here we use the linearized inversion method developed by Michael [1984]; this algorithm has been shown to produce optimal stress directions that closely agree with independent estimates made using borehole data [Townend and Zoback, 2004]. The algorithm is used to estimate three angles specifying the orientation of the principal stress axes and a fourth parameter, $\phi=\left(S_{2}-S_{3}\right) /\left(S_{1}-S_{3}\right)$ [after Angelier, 1979], representing the relative principal stress magnitudes or equivalently the shape of the stress ellipsoid. $S_{1}$ is the axis of maximum compressive stress (as noted above), $S_{2}$ is the axis of intermediate compressive stress, and $S_{3}$ is the axis of minimum compressive stress. These four parameters are sufficient to compute the true axis of greatest horizontal compressive stress, $S_{\mathrm{Hmax}}$; this transformation does not require the principal stress magnitudes to be known independently [Lund, 2000].

[19] Before computing the stress parameters, we employ a nonhierarchical clustering algorithm (K-means [e.g., Hartigan, 1975]) to subdivide the focal mechanism catalog on the basis of each earthquake's hypocentral coordinates. This approach is similar to the recursive gridding method we have used previously [Townend and Zoback, 2001, 2004], but differs in that we base the clusters solely on the distance between earthquakes (with depths weighted by a factor of 10 so that clusters tend to be more extensive in the horizontal plane than in the vertical direction) and do not use a square grid. Doing so enables us to compute stress directions with as high a spatial resolution as the data themselves warrant, and to obtain stress estimates at different depths. Although the K-means algorithm does not generally find the globally optimum cluster positions, it is guaranteed to partition the data so that each data point (hypocenter) is closer to its cluster's centroid than to any 


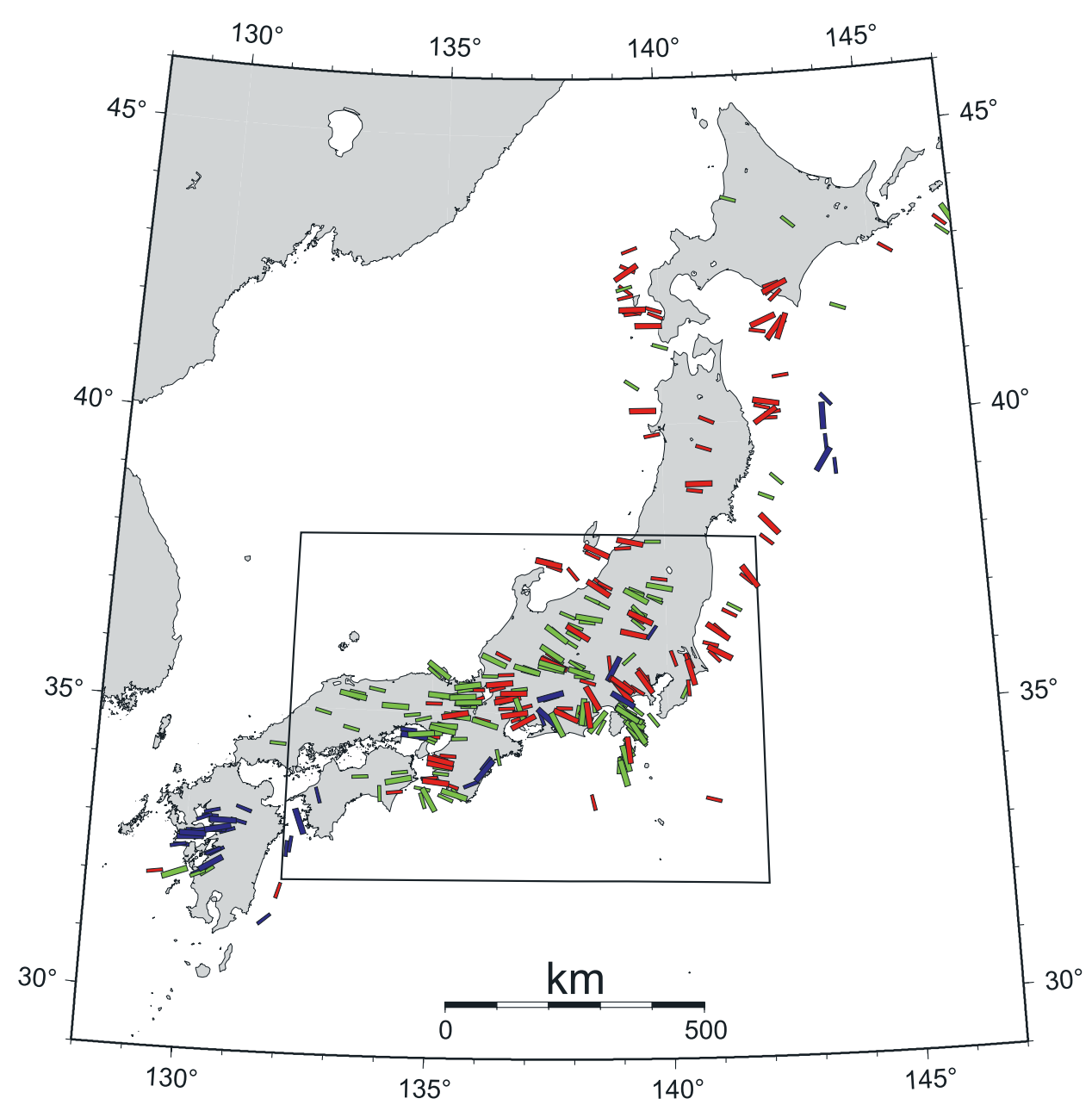

Figure 4. Axis of maximum horizontal compressive stress $\left(S_{\mathrm{Hmax}}\right)$ estimated throughout Japan for clusters of more than 20 focal mechanisms shallower than $35 \mathrm{~km}$. Normal, strike-slip, and reverse stress states are shown in blue, green, and red, respectively, and the large and small symbols represent stress orientations computed with and without restricting the focal mechanism data to those with strike, dip, and rake uncertainties of $\leq 10^{\circ}$. The box demarcates the area of central Japan shown in Figures 5 and 6 .

other cluster's centroid [Hartigan, 1975]. We ran the clustering algorithm 30 times and used the clustering solution for which the sum over all $k$ clusters of the within-cluster summed centroid-hypocenter distances was a minimum. On the basis of previous experience with the stress inversion algorithm [Townend and Zoback, 2001, 2004] and some experimentation, we set the mean cluster size to be 40 focal mechanisms, and computed stress parameters only for those clusters containing more than 20 focal mechanisms.

[20] Figure 4 illustrates maximum horizontal compressive stress $\left(S_{\text {Hmax }}\right)$ directions computed using earthquakes throughout Japan with hypocenter depths of less than $35 \mathrm{~km}$. The $\sim 17,000$ earthquakes meeting this criterion were grouped into 424 clusters, of which 314 contained sufficient ( $\geq 20)$ focal mechanisms to warrant computing the stress tensor parameters. A separate set of results was obtained for 104 of the 149 clusters of $\sim 6,000$ focal mechanisms shallower than $35 \mathrm{~km}$ whose strike, dip, and rake uncertainties were less than $10^{\circ}$. Overall, the effect of including some less well determined observations in the stress calcu- lations appears to be minor. In both sets of results, some clear patterns emerge: (1) $S_{\mathrm{Hmax}}$ directions at nearby locations exhibit a high degree of similarity, although which of the principal stresses is subvertical appears to vary somewhat as indicated by either normal and strike-slip stress tensor results (implying $\mathrm{S}_{1} \sim \mathrm{S}_{2}$ ) or strike-slip and reverse stress tensor results in close proximity $\left(\mathrm{S}_{2} \sim \mathrm{S}_{3}\right)$; (2) normal faulting in the outer rise of the Japan Trench $\left(\sim 143.5^{\circ} \mathrm{E}\right.$, $\sim 40.0^{\circ} \mathrm{N}$ ) and southwest Nankai Trough east of Kyushu $\left(\sim 132^{\circ} \mathrm{E}, \sim 32^{\circ} \mathrm{N}\right)$ is clearly discriminated in the computed stress directions from forearc reverse faulting; (3) northern Honshu and Hokkaido exhibit a systematic SE-NW $S_{\mathrm{Hmax}}$ orientation and strike-slip or reverse faulting conditions; (4) $S_{\text {Hmax }}$ is oriented approximately ENE-WSW in southwestern Honshu, Shikoku, and Kyushu, with strike-slip and reverse faulting predominating in Honshu and Shikoku, and strike-slip and normal faulting predominating in Kyushu; and (5) $S_{\text {Hmax }}$ rotates in central Japan between the orientations characteristic of northern and southwestern Japan in a fan-shaped pattern emanating from north of the Izu Peninsula. 


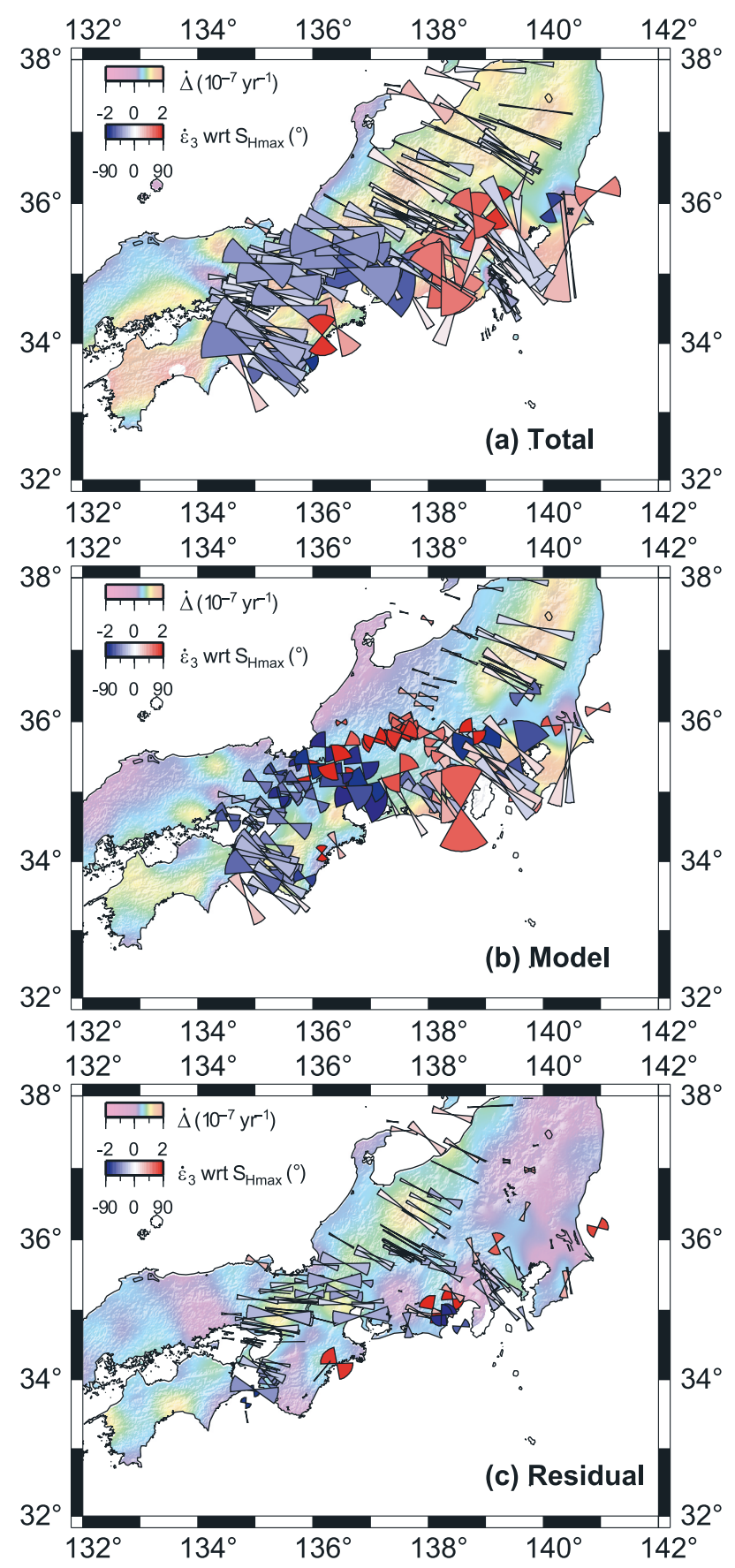

Figure 5. Rotational wedges illustrating the angular difference between the azimuths of the axis of maximum horizontal compressive stress $\left(S_{\mathrm{Hmax}}\right)$ and the axis of greatest contractional strain rate $\left(\dot{\epsilon}_{3}\right)$ for the (a) total, (b) modeled, and (c) residual strain rate fields. Red and blue denote locations at which $S_{\mathrm{Hmax}}$ is oriented clockwise and counterclockwise of $\dot{\epsilon}_{3}$, respectively; the darker shades correspond to larger angular differences. Each stress estimate has been compared with its nearest neighboring strain rate estimate, as long as the nearest neighbor is within $35 \mathrm{~km}$. The rotational wedges are overlain on maps of areal contraction rate, $\dot{\Delta}$ (i.e., negative dilatation rate; data modified after Mazzotti et al. [2001]).
[21] This last point, the regional rotation of $S_{\mathrm{Hmax}}$ from a well-developed ENE-WSW orientation west of $\sim 136^{\circ}$ to a WNW-ESE orientation in the northeast of the region, is of particular interest. Seismicity south of the Izu Peninsula reveals a pronounced N-S direction of maximum compression, altering to a more NW-SE orientation immediately east of the peninsula. The use of focal mechanisms of different depths, especially given the clustering algorithm's bias toward horizontal clusters and notwithstanding the relatively restricted depth range of interest $(35 \mathrm{~km})$, juxtaposes stress estimates from different crustal levels when displayed in plan view, notably in the Tokai region west of the Izu Peninsula. Here, the more northerly $S_{\text {Hmax }}$ orientation is associated with earthquakes deeper than 15-20 km, whereas with very few exceptions the rest of the seismicity contributing to the central Japan stress results, including those south and east of the Izu Peninsula, is upper crustal. Such rotations of stress orientation with depth are rare worldwide [cf. Zoback, 1992] and in this case probably represent a slight contamination of the focal mechanism catalog by subducted PHS slab seismicity.

\section{Stress, Strain, and Mountain Building}

[22] Each focal mechanism in a seismicity catalog presumably describes, to first order, frictional slip on a planar surface. As noted above, it is possible to relate a suite of such discontinuous slip processes to the continuous bulk strain in a region via moment tensor summation [e.g., Kostrov, 1974], but this calculation is dominated by the focal mechanisms of the largest magnitude earthquakes and consequently subject to a variety of catalog completeness issues. In contrast, computing regional stress tensor parameters does not make use of magnitude information, and has been shown in numerous studies to give stress estimates compatible with those from other observations including borehole deformation, geologic features, and large-scale lithospheric force balance calculations in areas such as the western United States [Zoback et al., 2003; Townend and Zoback, 2004]. An outstanding question, however, is whether the stress axes inferred from earthquake data bear a straightforward geometric relationship to the strain rate axes documented using geodetic techniques.

[23] If the deformation processes manifest in the seismologically determined stress field and the geodetically determined strain rate field were the same, we would expect to find that the axes of greatest horizontal compressive stress $\left(S_{\text {Hmax }}\right)$ and greatest contractional strain rate $\left(\dot{\epsilon}_{3}\right)$ were parallel [cf. Flesch et al., 2000, 2001]. That is, we might anticipate the crust to contract in the direction of greatest compression. However, a comparison of the stress results in central Japan illustrated in Figure 4 with the observed principal strain rate directions corresponding to the velocities illustrated in Figure 2a [after Mazzotti et al., 2001] reveals reasonably large angular discrepancies (Figure 5a) between the $S_{\mathrm{Hmax}}$ and $\dot{\epsilon}_{3}$ directions throughout much of central Japan and especially in the Chubu, Kinki, and Tokai districts. Note that in computing these discrepancies, we have compared only the nearest neighboring pairs of stress and strain rate orientations, and then only when the two observation points are less than $35 \mathrm{~km}$ apart; the stress data used here are those computed without the $10^{\circ}$ focal mech- 
anism parameter constraint. The rotational wedges shown in Figure 5 are colored to indicate whether $S_{\mathrm{Hmax}}$ is oriented at an acute angle clockwise (red) or counterclockwise of $\dot{\epsilon}_{3}$ (blue). There does not appear to be a systematic dependence of the discrepancy between the stress and strain rate directions on the magnitude of the strain rate field, here represented by the radius of each wedge and the colors of the underlying map.

[24] $S_{\text {Hmax }}$ is substantially more discrepant with respect to the axis of greatest contractional strain rate associated with subduction zone locking (Figure 5b); that is, the wedges have generally large angular extents, which exceed $30^{\circ}$ in many cases, and are colored correspondingly darker than in Figure 5a. Interestingly, therefore, while the modeled strain rates are a best fitting explanation in terms of a back-slip dislocation model of the observed strain rates, they provide a poorer description of stress orientations in central Japan than the original strain rate directions themselves.

[25] In contrast, a comparison of the $S_{\mathrm{Hmax}}$ directions with the residual strain rate orientations reveals a high degree of correlation throughout much of central Japan (Figure 5c), and appreciably smaller angular discrepancies than for either the total or model strain rate fields. In detail, the fan-shaped rotation of $S_{\mathrm{Hmax}}$ in the Chubu and Kinki regions west of $139^{\circ}$ is matched by a similar rotation of $\dot{\epsilon}_{3}$, from approximately SE-NW in the northern Japanese Alps $\left(138^{\circ} \mathrm{E}, 37^{\circ} \mathrm{N}\right)$ to $\mathrm{E}-\mathrm{W}$ north of the Kii Peninsula $\left(136^{\circ} \mathrm{E}\right.$, $\left.35^{\circ} \mathrm{N}\right)$. The agreement between the stress and residual strain rate tensor orientations is less convincing elsewhere, particularly in central Kanto and Tokai. The locking model employed by Mazzotti et al. [2001] systematically underestimates horizontal velocities along the southern coast of Shikoku, and therefore produces trench-perpendicular residual contraction at rates higher than observed by other authors [Mazzotti et al., 2000; S. Mazzotti, personal communication to J. Townend, 2002]. Hence the discrepancy between the residual contraction direction and the axis of greatest compressive stress in Shikoku may stem from problems associated with the locking model in that particular region.

\section{Discussion}

[26] On the basis of the comparisons illustrated in Figure 5, we infer that the crustal stress field in central Japan is most consistent, in terms of the axes of stress and strain rate being parallel, with a strain rate field from which the effects of subduction zone locking have been removed. This suggests that the seismologically observable stress field here is not directly related to flexure of the upper plate in response to subduction zone locking and cyclic strain accumulation and release. The stress results reinforce previous authors' observations that $S_{\mathrm{Hmax}}$ is not generally trench-perpendicular, as might be expected above a shallowly dipping subduction zone. Wang [2000] demonstrated that a weak subduction thrust is necessary for the $S_{1}$ stress axis and the $\dot{\epsilon}_{3}$ strain rate axis in the upper plate to be nonparallel. A weak (i.e., low friction) subduction thrust does not appear, however, to be a sufficient condition and leaves unanswered the question of why $S_{\mathrm{Hmax}}$ and the $\dot{\epsilon}_{3}$ resulting from locking of the subduction zone are almost orthogonal. Our results suggest that the stress field, and therefore the faulting characteristics and focal mechanisms of crustal seismicity from which it has been determined, is predominantly a manifestation of the Amurian plate's collision with northeast Japan. The strain rates associated with this process are smaller than those produced by interseismic locking of the subduction thrust, which dominate the geodetic image of deformation in central Japan [cf. Wang, 2000; Miyazaki and Heki, 2001].

[27] The distribution of residual strain rates is broadly coincident with the area of pronounced topography (Figure 6a) and high heat flow (Figure 6c) [Fukahata and Matsu'ura, 2001] in central Japan. This has been commented on before, most recently by Iio et al. [2002, 2004], who reviewed a range of previous models describing strain localization in central Japan. Iio et al. [2002, 2004] discussed the difficulty of focusing strain to the extent observed using kinematic models based on a subseismogenic zone detachment, collision and down flow, or slip on a lower crustal fault. They postulated that a more plausible mechanism is a wholesale weakening of the lower crust associated with the presence of water beneath western central Japan. A similar argument was made by Yamasaki and Seno [2005], who ascribed high strain rates in central Japan to a reduction in the mantle wedge's viscosity caused by slab dehydration.

[28] An alternative interpretation is that the spatial extent of residual deformation is controlled by patterns of crustal heat flow. This idea has been explored recently by Hyndman et al. [2005], who suggested that most zones of distributed continental deformation lie within the hot, back-arc regions of currently or recently active subduction zones. The high heat flow typical of such regions was argued by Hyndman et al. [2005] to represent asthenospheric convection facilitated by water fluxed from the subducted slab.

[29] The force-limited lithospheric strength model [Liu and Zoback, 1997; Townend and Zoback, 2001; Zoback et $a l ., 2002]$ presumes that the lithosphere deforms at the unique rate for which its integrated strength is equal to the assumed magnitude of plate-driving forces $(\sim 1-5 \times$ $10^{12} \mathrm{~N} \mathrm{~m}^{-1}$ ). In this context, lateral variations in heat flow are expected to be associated with vertical variations in ductile creep strength, $\eta(z)=\Delta S(z) / \dot{\epsilon}$, where $\Delta S(z)=S_{1}(z)-$ $S_{3}(z)$ is the differential stress as a function of depth. In particular, for a given crustal structure, increasing the surface heat flow results in a lower proportion of the lithosphere's total strength being provided via brittle failure mechanisms in the seismogenic crust, and a correspondingly higher proportion being provided by the rapidly deforming ductile lower crust and lithospheric mantle [Zoback et al., 2002].

[30] While the force-limited strength model was originally described in an idealized one-dimensional form to explain the strength of intraplate lithosphere [Liu and Zoback, 1997; Townend and Zoback, 2001], it is useful to consider whether it might be applicable more generally. We have previously suggested that the Coast Ranges in California are a manifestation of thermally modulated strain rates in a uniform tectonic stress field [Zoback et al., 2002]. It appears that a similar correspondence may also exist in central Japan between heat flow, topographic relief, and deformation that is not recovered during a complete cycle of subduction zone strain accumulation and release. In both 
locations, the style of deformation associated with the high relief is different from that predicted on the basis of dislocation models. Reverse faulting perpendicular to the San Andreas fault in the Coast Ranges is difficult to reconcile with the geodetically detectable but insignificant rate of fault-normal contraction of $-0.9 \pm 7.9 \times 10^{-9} \mathrm{yr}^{-1}$ [Savage et al., 2004], but is compatible with the observed near-fault-normal $S_{\mathrm{Hmax}}$ direction [Townend and Zoback, 2004].

[31] With respect to possible thermal constraints on upper plate deformation central Japan, we have not taken into consideration either variations in crustal thickness or the effect on surface heat flow of active uplift and erosion. As

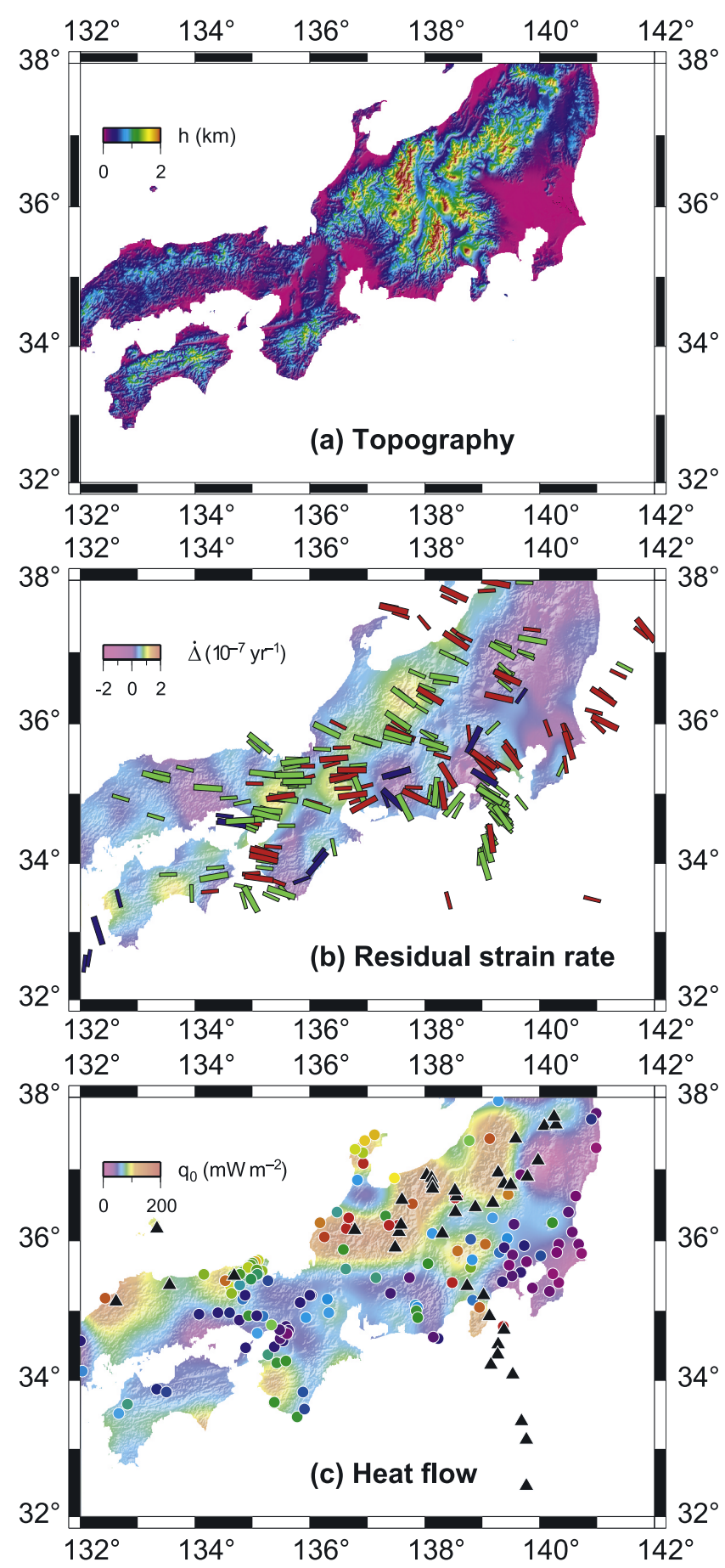

Iio et al. [2002] and Hyndman et al. [2005] have argued, water driven off the subducting slab may ultimately be responsible for concentrated deformation, either via a direct mechanical weakening effect [Iio et al., 2002] or via its deep-seated influence on shallow mantle convection and heat flow [Hyndman et al., 2005]. Interestingly, the highest residual strain rates and topographic elevations occur where the Philippine Sea and Pacific plates interleave [Ishida, 1992], and where the volume of devolved water might consequently be anomalously large. In this case, while the high crustal temperatures might be the key control on upper plate strength, and the localization of long-term deformation, the ultimate smoking gun might be the subducted plates.

[32] To summarize, the congruence of the $S_{\mathrm{Hmax}}$ and residual $\dot{\epsilon}_{3}$ axes illustrated in Figure 5c and the spatial coincidence of high residual strain rates, high topographic relief, and high surface heat flow illustrated in Figure 6 suggest that long-term deformation in central Japan reflects horizontal collision between northeast and southwest Honshu [Mazzotti et al., 2001; Miyazaki and Heki, 2001] and is not necessarily interpretable using models based primarily on subduction processes. Nevertheless, if the underlying cause of the high heat flow is the presence of two interleaved slabs, PHS and PAC, then deformation associated with mountain building in central Japan might best be viewed as the combined result of subduction-related thermal modulation of a collision-related stress field.

\section{Conclusions}

[33] Modern geodetic and seismographic networks enable patterns of crustal deformation and seismicity to be determined with unprecedented accuracy and detail. To date, however, little effort has been made to determine how the different tectonic signals recorded geodetically and seismologically are related. In this study, comparisons of crustal strain rates computed from geodetic observations with crustal stress directions determined from seismological data reveal that much of the deformation occurring in central Japan is not associated with subduction per se but rather with collision of southwest Japan with northeastern Honshu.

Figure 6. (a) Topographic relief map of central Japan. All elevations higher than $2 \mathrm{~km}$ are red. (b) Axis of maximum horizontal compression $\left(S_{\mathrm{H} \max }\right)$ computed for clusters of more than 20 focal mechanisms shallower than $35 \mathrm{~km}$. Normal, strike-slip, and reverse stress states are shown in blue, green, and red, respectively, and the large and small symbols represent stress orientations computed with and without restricting the focal mechanism data to those with strike, dip, and rake uncertainties of $\leq 10^{\circ}$. The underlying map is of the residual areal contraction rate field (Figure 5c). (c) Heat flow map of central Japan [Yamano, 1995]. The dots indicate measurement sites; only those measurements less than $200 \mathrm{~mW} \mathrm{~m}^{-2}$ have been used [cf. Fukahata and Matsu'ura, 2001], and the resulting surface has been lowpass filtered to retain only those features with wavelengths longer than $100 \mathrm{~km}$. No correction has been applied for the thermal effects of Quaternary uplift and erosion [Harayama, 1992]. Black triangles denote the locations of volcanoes active during the Holocene. 
[34] Previous authors have used geodetic data to compute the horizontal crustal strain rate field and attempted to distinguish a component of the total strain rate field associated with contemporary locking of the Nankai Trough and Japan Trench subduction interfaces [Mazzotti et al., 2001; Miyazaki and Heki, 2001]. In those studies, the residual strain rates exhibit spatial patterns, magnitudes, and orientations suggesting that they are meaningful representations of real deformation, rather than unmodeled errors. In particular, Mazzotti et al. [2001] concluded that the localization of residual strain rates in the western area of central Japan is a robust observation and not solely an artifact stemming from an inappropriate locking model.

[35] Our observations reveal that the $S_{\mathrm{Hmax}}$ horizontal stress axis in central Japan exhibits a high degree of congruence with the residual $\dot{\epsilon}_{3}$ horizontal strain rate axis. This bolsters previous authors' conclusions that the residual strain rates have a physical significance, and are not merely unmodeled errors. Further, these observations suggest that part of the apparent discrepancy between crustal stress and strain rate directions stems from a comparison of parameters representing processes occurring at different timescales. In the particular case of central Japan, it appears that the highfrequency, relatively low-magnitude strain rates associated with subduction zone locking do not greatly affect the crustal stress field, whereas long-term horizontal motion between northeast and southwest Japan is more evident in the crustal stress field than in the total strain rate field. We suggest that localization of long-term, irrecoverable deformation in central Japan is a consequence of the higher heat flow in that area than elsewhere. In this context, mountain building in the Japanese Alps appears to be related more to crustal collision than to subduction.

[36] Acknowledgments. We are grateful to staff at the National Institute for Earth Science and Disaster Prevention, the Earthquake Research Institute, and the Japanese Meteorological Agency for their assistance with obtaining the seismicity data; to Shin'ichi Miyazaki and Stéphane Mazzotti for kindly sharing and discussing their geodetic results; to Phil Cummins (Geoscience Australia) for help in merging the seismicity catalogs; and to the Japan Marine Science and Technology Center (JAMSTEC) and a Stanford Lieberman Fellowship for financial support. The thought-provoking comments of two anonymous reviewers are also appreciated. The stress results reported here have been submitted to the World Stress Map database (http://www.world-stress-map.org/)

\section{References}

Abers, G. A., and J. W. Gephart (2001), Direct inversion of earthquake first motions for both the stress tensor and focal mechanisms and application to southern California, J. Geophys. Res., 106, 26,523-26,540.

Aki, K., and P. G. Richards (1980), Quantitative Seismology, 1st ed., W. H. Freeman, New York.

Angelier, J. (1979), Determination of the mean principal directions of stresses for a given fault population, Tectonophysics, 56, T17-T26.

Angelier, J. (1984), Tectonic analysis of fault slip data sets, J. Geophys. Res., 89, 5835-5848.

Baba, T., T. Hori, S. Hirano, P. Cummins, J.-O. Park, M. Kameyama, and Y. Kaneda (2001), Deformation of a seamount subducting beneath an accretionary prism: Constraints from numerical simulation, Geophys. Res. Lett., 28, 1827-1830.

Brace, W. F., and D. Kohlstedt (1980), Limits on lithospheric stress imposed by laboratory measurements, J. Geophys. Res., 85, 62486252.

DeMets, C., R. Gordon, D. Argus, and S. Stein (1994), Effect of recent revisions to the geomagnetic reversal time scale on estimates of current plate motions, Geophys. Res. Lett., 21, 2191-2194.

Flesch, L. M., W. E. Holt, A. J. Haines, and B. Shen-Tu (2000), Dynamics of the Pacific-North American plate boundary in the western United States, Science, 287, 834-836.
Flesch, L. M., A. J. Haines, and W. E. Holt (2001), Dynamics of the IndiaEurasia collision zone, J. Geophys. Res., 106, 16,435-16,460.

Fukahata, Y., and M. Matsu'ura (2001), Correlation between surface heat flow and elevation and its geophysical implication, Geophys. Res. Lett., $28,2703-2706$

Gephart, J. W. (1990), Stress and the direction of slip on fault planes, Tectonics, 9, 845-858.

Gordon, R. G. (1998), The plate tectonic approximation: Plate nonrigidity, diffuse plate boundaries, and global plate reconstructions, Аппи. Rev. Earth Planet. Sci., 26, 615-642.

Harayama, S. (1992), Youngest exposed granitoid pluton on Earth: Cooling and rapid uplift of the Pliocene-Quaternary Takidani Granodiorite in the Japan Alps, central Japan, Geology, 20, 657-660.

Hartigan, J. A. (1975), Clustering Algorithms, 351 pp., John Wiley, Hoboken, N. J.

Hassani, R., D. Jongmans, and J. Chéry (1997), Study of plate deformation and stress in subduction zone processes using two-dimensional numerical models, J. Geophys. Res., 102, 17,951-17,965.

Heki, K., S. Miyazaki, H. Takahashi, M. Kasahara, F. Kimata, S. Miura, N. Vasilenko, A. Ivashchenko, and K.-D. An (1999), The Amurian plate motion and current plate kinematics in eastern Asia, J. Geophys. Res., 104, 29,147-29,155.

Henry, P., S. Mazzotti, and X. Le Pichon (2001), Transient and permanent deformation of central Japan estimated by GPS: 1. Interseismic loading and subduction kinematics, Earth Planet. Sci. Lett., 184, 443-453.

Hyndman, R., K. Wang, and M. Yamano (1995), Thermal constraints on the seismogenic portion of the southwestern Japan subduction thrust, J. Geophys. Res., 100, 15,373-15,392.

Hyndman, R., C. Currie, and S. Mazzotti (2005), Subduction zone backarcs, mobile belts, and orogenic heat, GSA Today, 15, 4-10, doi:10.1130/ 1052-5173(2005)015.

Hyodo, M., and K. Hirahara (2003), A viscoelastic model of interseismic strain concentration in Niigata-Kobe Tectonic Zone of central Japan, Earth Planets Space, 55, 667-675.

Iio, Y., T. Sagiya, Y. Kobayashi, and I. Shiozaki (2002), Water-weakened lower crust and its role in the concentrated deformation in the Japanese islands, Earth Planet. Sci. Lett., 203, 245-253.

Iio, Y., T. Sagiya, and Y. Kobayashi (2004), Origin of the concentrated deformation zone in the Japanese Islands and stress accumulation process of intraplate earthquakes, Earth Planets Space, 56, 831-842.

Ishida, M. (1992), Geometry and relative motion of the Philippine Sea plate and Pacific plate beneath the Kanto-Tokai district, Japan, J. Geophys. Res., 97, 489-513.

Klein, F. (2002), User's guide to Hypoinverse-2000, a Fortran program to solve for earthquake locations and magnitudes, version 1.0, U.S. Geol. Surv. Open File Rep., 02-171.

Kostrov, B. V. (1974), Seismic moment and energy of earthquakes, and seismic flow in rocks, Izv. Phys. Solid Earth, 1, 22-44.

Lewis, J. C., J. R. Unruh, and R. J. Twiss (2003), Seismogenic strain and motion of the Oregon coast block, Geology, 31, 183-186.

Liu, L., and M. D. Zoback (1997), Lithospheric strength and intraplate seismicity in the New Madrid seismic zone, Tectonics, 16, 585-595.

Lund, B. (2000), Crustal stress studies using microearthquakes and boreholes, Ph.D. thesis, Uppsala Univ., Uppsala, Sweden.

Mazzotti, S., P. Henry, X. Le Pichon, and T. Sagiya (1999), Strain partitioning in the zone of transition from Nankai subduction to Izu-Bonin collision (central Japan): Implications for an extensional tear within the subducting slab, Earth Planet. Sci. Lett., 172, 1-10.

Mazzotti, S., X. Le Pichon, P. Henry, and S. Miyazaki (2000), Full interseismic locking of the Nankai and Japan-west Kurile subduction zones: An analysis of uniform elastic strain accumulation in Japan constrained by permanent GPS, J. Geophys. Res., 105, 13,159-13,177.

Mazzotti, S., P. Henry, and X. Le Pichon (2001), Transient and permanent deformation of central Japan estimated by GPS: 2 . Strain partitioning and arc-arc collision, Earth Planet. Sci. Lett., 184, 455-469.

McKenzie, D. (1969), The relationship between fault plane solutions for earthquakes and the directions of the principal stresses, Bull. Seismol. Soc. Am., 59, 591-601.

Michael, A. J. (1984), Determination of stress from slip data: Faults and folds, J. Geophys. Res., 89, 11,517-11,526.

Miyazaki, S., and K. Heki (2001), Crustal velocity field of southwest Japan: Subduction and arc-arc collision, J. Geophys. Res., 106, 4305-4326.

Nakamura, K., and S. Uyeda (1980), Stress gradient in arc-back arc regions and plate subduction, J. Geophys. Res., 85, 6419-6428.

Reasenberg, P. A., and D. Oppenheimer (1985), Fpfit, Fpplot, and Fppage: Fortran computer programs for calculating and displaying earthquake fault-plane solutions, U.S. Geol. Surv. Open File Rep., 85-739.

Sagiya, T., S. Miyazaki, and T. Tada (2000), Continuous GPS array and present-day crustal deformation of Japan, Pure Appl. Geophys., 157, $2303-2322$. 
Savage, J. C., W. Gan, W. H. Prescott, and J. L. Svarc (2004), Strain accumulation across the Coast Ranges at the latitude of San Francisco, 1994-2000, J. Geophys. Res., 109, B03413, doi:10.1029/ 2003JB002612.

Seno, T. (1999), Syntheses of the regional stress fields of the Japanese islands, Island Arc, 8, 66-79.

Shiono, K., T. Mikumo, and Y. Ishikawa (1980), Tectonics of the KyushuRyukyu arc as evidenced from seismicity and focal mechanism of shallow to intermediate-depth earthquakes, J. Phys. Earth, 28, 17-43.

Sibson, R. H. (1974), Frictional constraints on thrust, wrench and normal faults, Nature, 249, 542-544

Tabei, T., M. Hashimoto, S. Miyazaki, and Y. Ohta (2003), Present-day deformation across the southwest Japan arc: Oblique subduction of the Philippine Sea plate and lateral slip of the Nankai forearc, Earth Planets Space, 55, 643-647.

Thatcher, W. (1995), Microplate versus continuum descriptions of active tectonic deformation, J. Geophys. Res., 100, 3885-3894.

Townend, J., and M. D. Zoback (2000), How faulting keeps the crust strong, Geology, 28, 399-402.

Townend, J., and M. D. Zoback (2001), Implications of earthquake focal mechanisms for the frictional strength of the San Andreas fault system, in The Nature and Significance of Fault Zone Weakening, edited by R. E. Holdsworth et al., Geol. Soc. Spec. Publ., 186, 13-21.

Townend, J., and M. D. Zoback (2004), Regional tectonic stress near the San Andreas fault in central and southern California, Geophys. Res. Lett., 31, L15S11, doi:10.1029/2003GL018918.

Tsukahara, H., and R. Ikeda (1991), Crustal stress orientation pattern in the central part of Honshu, Japan: Stress provinces and their origins (in Japanese), J. Geol. Soc. Jpn., 97, 461-474.

Tsukahara, H., and Y. Kobayashi (1991), Crustal stress in the central and western parts of Honshu, Japan (in Japanese), J. Seismol. Soc. Jpn., 44, $221-231$.

Ukawa, M., M. Ishida, S. Matsumura, and K. Kasahara (1984), Hypocenter determination method of the Kanto-Tokai observational network for microearthquakes (in Japanese), Res. Notes 53, Natl. Res. Inst. for Earth Sci. and Disaster Prev., Tokyo.
Wallace, L. M., J. Beavan, R. McCaffrey, and D. Darby (2004), Subduction zone coupling and tectonic block rotations in the North Island, New Zealand, J. Geophys. Res., 109, B12406, doi:10.1029/2004JB003241.

Wang, K. (2000), Stress-strain "paradox", plate coupling, and forearc seismicity at the Cascadia and Nankai subduction zones, Tectonophysics, 319, 321-338.

Wang, K, and J. He (1999), Mechanics of low-stress forearcs: Nankai and Cascadia, J. Geophys. Res., 104, 15,191-15,205.

Yamano, M. (1995), Recent heat flow studies in and around Japan, in Terrestrial Heat Flow and Geothermal Energy in Asia, edited by M. L. Gupta and M. Yamano, pp. 173-201, IBH Publ., New Delhi.

Yamasaki, T., and T. Seno (2005), High strain rate zone in central Honshu resulting from the viscosity heterogeneities in the mantle, Earth Planet. Sci. Lett., 232, 13-27.

Zhao, S., and S. Takemoto (2000), Deformation and stress change associated with plate interaction at subduction zones: A kinematic modelling, Geophys. J. Int., 142, 300-318.

Zhao, S., X. Wu, T. Hori, Y. Kaneda, and S. Takemoto (2004), Crustal deformation and stress localization in Kanto-Tokai, central Japan revealed by GPS, Geophys. J. Int., 157, 737-752.

Zoback, M. D., J. Townend, and B. Grollimund (2002), Steady-state failure equilibrium and deformation of intraplate lithosphere, Int. Geol. Rev., 44, $383-401$

Zoback, M. D., et al. (2003), Determination of stress orientation and magnitude in deep wells, Int. J. Rock Mech. Min. Sci., 40, 1049-1076.

Zoback, M. L. (1992), First- and second-order patterns of stress in the lithosphere: The World Stress Map Project, J. Geophys. Res., 97, $11,703-11,728$

J. Townend, School of Earth Sciences, Victoria University of Wellington, P.O. Box 600, Wellington, New Zealand. (john.townend@vuw.ac.nz)

M. D. Zoback, Department of Geophysics, Stanford University, Stanford, CA 94305-2215, USA. (zoback@pangea.stanford.edu) 